\title{
Factors associated with stunting among children of age 24 to 59 months in Meskan district, Gurage Zone, South Ethiopia: a case-control study
}

Teshale Fikadu', Sahilu Assegid² and Lamessa Dube ${ }^{2 *}$

\begin{abstract}
Background: Stunting is one of the major causes of morbidity among under-five children Knowledge about risk factors of stunting is an important precondition for developing and strengthening nutritional intervention strategies. The purpose of this study was to assess factors associated with stunting among children of age 24 to 59 months in Meskan District of Gurage Zone, South Ethiopia.
\end{abstract}

Methods: Community based case-control study was conducted among children of age 24 to 59 months. A multistage sampling technique was used to select the study participants. Cases were stunted children while controls were not stunted children. A total of 121 cases and 121 controls were studied.. Data were analyzed using SPSS 16.0 statistical software.

Results: Children living in households with eight to ten [Adjusted Odds Ratio (AOR) $=4.44,95 \% \mathrm{Cl}: 1.65,11.95$ ] and five to seven $[A O R=2.97,95 \% \mathrm{Cl}: 1.41,6.29]$ family members were more likely to be stunted than those living in households with two to four family members. Similarly, children living in households with three under-five children $[A O R=3.77,95 \%$ Cl: 1.33, 10.74] were more likely to develop stunting than those living in households with one under-five child. Children whose mothers worked as merchants [AOR $=4.03,95 \% \mathrm{Cl}: 1.60,10.17]$ were more likely to be stunted than children whose mothers worked as house wives. Children who breast fed for $<2$ years [AOR $=5.61,95 \% \mathrm{Cl}: 1.49,11.08]$ were more likely to be stunted than those who breast fed $\geq 2$ years. Children who were exclusively breast fed for $<6$ months [AOR $=$ 3.27, $95 \%$ Cl: 1.21, 8.82]were more likely to develop stunting than children who were exclusively breast fed for the first 6 months. Children who bottle fed $[\mathrm{AOR}=3.30,95 \% \mathrm{Cl}: 1.33,8.17)]$ were more likely to be stunted than children who fed their complementary food using spoon/cup.

Conclusions: Family size, number of under-five children in the household, maternal occupation, duration of exclusive breastfeeding, duration breast feeding, and method of feeding complementary food were independently associated with stunting. Thus, public health intervention working on improving child nutrition should consider these determinants.

Keywords: Stunting, Children, Factors, Ethiopia

\section{Background}

Adequate provision of nutrients is crucial to ensure good physical \& mental development as well as for long-term health. Undernutrition accounts $35 \%$ of all deaths among under-five children. More than 2 million under-five children die each year due to undernutrition [1]. Undernutrition refers to a state resulting from a relative or absolute deficiency of one or more essential nutrients.

\footnotetext{
* Correspondence: dubelamessa@yahoo.com

${ }^{2}$ College of Public Health and Medical Sciences, Department of

Epidemiology, Jimma University, Jimma 378, Ethiopia

Full list of author information is available at the end of the article
}

The three main indicators used to define undernutrition, i.e., stunting, underweight and wasting; that represent different histories of nutritional insult to the child and measured by height for age, weight for height and weight for age indexes respectively. Stunting is a measure of chronic malnutrition. Undernutrition in low and middleincome countries was high. Both stunting \& underweight are highest in Eastern Africa. About $42 \%$ of children in sub-Saharan Africa and 182 million (32.5\%) children in developing countries were undernourished and the stunting trend was stagnant in Africa from1990 to 2010 [2-6]. 
Undernutrition can best be described in Ethiopia as a long term year round phenomenon due to chronic inadequacies of food combined with high levels of illness in under-five children which 44.0\%, 29.0\% \& $10.0 \%$ were stunted; underweight and wasted respectively [7]. Similarly $53.6 \%, 32.7 \%$ \& $7.0 \%$ of children aged 24 to 59 months were stunted, underweight and wasted respectively [7].

Studies show that stunting is associated with deprived attention, memory impairment, reduced learning, and memory in children, low school enrollment, and decreased higher cognitive functioning with a slowing in the rate of cognitive development. These finally result in low adult wages and lost productivity [8-10].

The causes of malnutrition are numerous and multifaceted. These causes are intertwined with each other and are hierarchically related. The most immediate determinants are poor diet and disease which are themselves caused by a set of underlying factors; household food security, maternal/child caring practices and access to health services and healthy environment. These underlying factors themselves are influenced by the basic factors (socio-economic and political conditions) [2,11].

Undernutrition are multiple and inextricably linked to poverty (low socioeconomic status). Many studies revealed that lowest prevalence of stunting was found among children from families with higher per capital income (socioeconomic status) [12-14]. When a child lives in an area of low income level the chance of disease increase and these diseases can increase the risk of stunting [15]. More children suffering from stunting were observed among mothers of low educational levels than those with high educational levels $[13,16,17]$. Under- five children living in a household with large family were at higher risk of being stunted. Similarly, under- five children living in households with more than one under-five were more likely to be stunted $[12,13,17]$. Studies conducted in Ethiopia and abroad reported that the quantity, frequency, and type of supplementary feeding, birth weight, sex, birth order and disease conditions like diarrhea were strongly associated with stunting among under-five children [13,15,18-30]. Housing environment such as lack of safe water supply, access to a toilet facility and inadequate sanitation were among the factors that increased the risk of stunting [20,25].

Comprehensive knowledge about the risk factors of stunting in local context is vital to reduce stunting rate, to develop prevention strategies and strengthen nutrition intervention programs. Despite higher prevalence of stunting among children age 24 to 59 months, there are limited studies that reports about risk factors of stunting among children age 24 to 59 months separately. Besides neither case-control nor cohort study was done to identify risk factors of stunting in the district. Thus the purpose of this study was to assess factors associated with stunting among children of age 24 to 59 months in Meskan district for the development and improvement of implementation and intervention strategies to reduce child mortality and morbidity.

\section{Methods}

Study setting, design and sampling

A community based case-control study was conducted from February to March 2013 in Meskan district, Gurage Zone, South Ethiopia. The district is located at 135 kilometers south of Addis Ababa (the capital city of Ethiopia). It had an estimated total population of 228,852 and under-five children of 35,724 from this about $61 \%$ (21970) were between the ages of 24 to 59 months in the year 2012/13 which is projected from 2007 Ethiopia Central Statistical Agency. The district has a total of 50 functioning health institutions (2 hospital 8 health center and 40 health posts).

Cases were stunted children aged 24 to 59 months: height-for age $\mathrm{z}$ - score below -2SD from the median height of the WHO reference population. While Controls were children aged 24 to 59 months without stunting.

Sample size was calculated using Epi info version 7 by assuming the proportion of mother with educational status of primary or less among controls and cases were $70.4 \%$ and $91.3 \%$ respectively [30], 95\% CI, $80 \%$ power, case to control ratio of $1: 1$, design effect of 2 and accounted for $10 \%$ possible non-response. The total sample size was 242 (121 cases and 121 controls). To calculate sample size, maternal education was chosen as an independent variable since it gave maximum sample size and study conducted in Uganda was used because we did not find the proportions among cases and controls of there was neither a study done of children ages of 24-59 months in Ethiopia. Design effect was used. The reason is two steps were required to reach or identify the study participants.

A multistage sampling technique was used. Two urban and thirteen rural kebeles (the smallest administration unit in Ethiopia) were selected out of 6 urban \& 40 rural kebeles by simple random sampling technique (lottery method) after stratifying the district in to urban and rural kebeles. All children of age 24 to 59 months living in selected kebeles were measured for their z-score of height for age and categorized as stunted and not stunted to generate sampling frames for cases and controls by a census conducted prior to the actual data collection. During the census 15,316 households were included from the 15 selected kebeles. A total of 7,367 (3,445 stunted and 3,922 not stunted) children between age of 24 to 59 months were measured for height for age. The total sample size of cases (stunted children) was allocated proportionally to the selected kebeles 
based on number of stunted children identified during census. Then simple random sampling method (generated by computer) was used to recruit cases from each selected kebele. A control was selected from the next house (neighbor) using a code of house number in ascending order. If two or more eligible controls were found in the same household then one of them was selected randomly.

\section{Measurements}

Thirty health extension workers were trained to carry out a census to identify source population of cases and controls group, via interviewing the mother and obtaining the anthropometric measurements of each child. During the census health extension workers measured the height and identified the age of each child aged between 24 and 59 months. Height was measured in a standing-up position to the nearest $0.1 \mathrm{~cm}$ using a standard vertical board with a detachable sliding headpiece. In rural areas it is very difficult to get the age correctly. This may leads to misclassification of cases and controls. Thus ages of children were estimated using Expanded Program of Immunization registration book or immunization card when possible and asking the mother. The indices were calculated using WHO Anthroplus version 3.2.2 statistical software.

Data were collected using structured questionnaire via face to face interview with participant's mothers or care takers. In this study the following independent variables or factors were assessed: religion, ethnicity, wealth index, family size, parental age, marital status, parental occupation, maternal knowledge, number of under-five children, source of drinking water, availability of toilet, waste disposal, antenatal care, place of delivery, immunization status, time of initiation of breast feeding, duration of exclusive breast feeding, duration of breast feeding, time of initiation of complementary feeding, type of complementary food, method of complementary feeding and number of meal per day, diarrhea, malaria and acute respiratory tract infections. In addition to these age, sex, type of birth (singleton or multiple), birth order of the child were also assessed. The questionnaire was initially prepared in English and translated into local language, then retranslated to check consistency. The instrument was pre-tested in $5 \%$ of sample size in non-selected kebele. The data were collected by five data collectors who have first degree in public health after two days training. Filled questionnaires were checked daily for its completeness by supervisors.

\section{Data analysis}

Data were checked for completeness, edited, coded and entered into Epi data version 3.1 and exported to SPSS 16.0 statistical software for analysis. Frequencies and cross tabulations were used to check consistency. Composite scales were constructed to represent a single construct.

In this study current maternal knowledge as a proxy of past maternal knowledge was assessed by eleven knowledge questions on breast feeding (time of initiation, exclusive breast feeding and duration breast feeding) and complementary feeding practices (time of starting, method of feeding and frequency). If a mother responds correctly $<60 \%, 60 \%-75 \%$ and $>75 \%$ of the total knowledge questions, she is considered as having poor, fair and god knowledge respectively. Wealth index was computed as a composite indicator of living standard based on variables related to ownership of selected household assets, agricultural land, quantity of livestock and materials used for housing construction. The computation was made using principal component analysis and a single continuous variable was generated by summing up the principal components into one. Quartiles of wealth index were generated using the composite score.

After cleaning data for inconsistencies and missing values, descriptive statistics were done. Then after, bivariate analysis was done for all explanatory variables to identify those associated with children stunting. Variables with p-value less than 0.25 in the bivariate analysis were included in a backward stepwise logistic regression procedure. Odds ratios (95\% confidence intervals) were calculated to determine the association between stunting and independent variables. Model fitness was assessed using Hosmer and Lemeshow test $(\mathrm{p}=0.697)$. Collinearity and interaction between independent variables were checked and not found. Data were presented using tables.

\section{Ethical consideration}

The ethical clearance was obtained from Jimma University, Ethical review board. Written consent was obtained from caretakers of under-five children. Child with no treated diarrhea, respiratory tack infection and fever/ malaria were referred to nearby health centre.

\section{Results}

A total of 242 children (121cases and 121 controls) were participated in this study. All of the study participants were singleton birth. Sixty five $(53.7 \%)$ of cases as well as controls were male. The median birth orders of cases \& controls were 4 and 3 respectively. Hundred thirteen (93.4\%) of children's mothers were Gurage by their ethnicity. Majority of participants' mothers, $97(80.2 \%)$ of cases and $90(74.3 \%)$ of controls, were Muslim by religion. Mothers of 68(56.2\%) and 59(48.8\%) of cases and controls were illiterate respectively. Nearly two fifth of the controls' mothers were house wife (Table 1).

Study participants (children) living in households with eight to ten [Adjusted Odds Ratio $(\mathrm{AOR})=4.44,95 \% \mathrm{CI}$ : 
Table 1 Socio-demographic characteristics of the study participants and their mothers in Meskan district, Gurage Zone, South Ethiopia, March 2013

\begin{tabular}{|c|c|c|c|c|c|c|c|}
\hline \multirow[t]{2}{*}{ Variable } & \multicolumn{2}{|c|}{ Case control } & \multirow{2}{*}{ p-value } & \multicolumn{4}{|l|}{ Number of under 5 children } \\
\hline & № (\%) & № $(\%)$ & & ( & $41(33.9)$ & $66(54.5)$ & (2001 \\
\hline Sex & & & & 2 & $60(49.6)$ & $48(39.7)$ & 0.001 \\
\hline Male & $65(53.7)$ & $65(53.7)$ & 0.89 & 3 & $20(16.5)$ & $7(5.8)$ & \\
\hline Female & $56(46.3)$ & $56(46.3)$ & & Birth order & & & \\
\hline Ethnicity & & & & $1-3$ & $53(43.8)$ & $61(50.4)$ & 0.36 \\
\hline Gurage & 113(93.4) & 113(93.4) & 0.80 & Above 3 & $68(56.2)$ & $60(49.6)$ & \\
\hline
\end{tabular}

Maternal Religion

Muslim

Orthodox

Protestant

Maternal education

Illiterate

Literate

Maternal Occupation

Farmer

Merchant

House wife

Father Occupation

Farmer

Merchant

Maternal age (in years)

20-24

25-29

30-34

above 35

Marital status

Married

Divorced/Widowed

Wealth index

$1^{\text {st }}$ Quartile

$2^{\text {nd }}$ Quartile

$3^{\text {rd }}$ Quartile

$4^{\text {th }}$ Quartile

97(80.2)

90(74.4)

16(13.2)

18(14.9)

$8(6.6)$

13(10.7)

68(56.2)

59(48.8)

53(43.8)

62(51.2)

50(41.3) 38(31.4)

26(21.5)

14(11.6)

45(37.2)

69(57.0)

102(84.3)

99(81.8)

19(15.7)

22(18.2)

6(5.0)

9(7.4)

$52(43.0)$

43(35.5)

$31(25.6)$

37(30.6)

$32(26.4)$

32(26.4)

110(90.9)

118(97.5)

11(9.1)

3(2.5)

35(28.9)

24(19.8)

36(29.8)

29(24.0)

26(21.5)

$31(25.6)$

21(17.4)

40(33.1)

Family size

2-4
$5-7$
8-10
Children age (in months)
$24-35$
$36-47$
$48-59$

24(19.8)

44(36.4)

$73(60.3)$

60(49.6)

24(19.8)

17(14)

48(39.7)

$30(24.8)$

48(39.7)

46(38.0)

25(20.6)
Table 1 Socio-demographic characteristics of the study participants and their mothers in Meskan district, Gurage Zone, South Ethiopia, March 2013 (Continued)

$1.65,11.95$ ] and five to seven [AOR $=2.97,95 \% \mathrm{CI}: 1.41$, 6.29] family members were more likely to be stunted than those living in households with two to four family members. Similarly, children living in households with three under-five children $[\mathrm{AOR}=3.77,95 \% \mathrm{CI}$ : 1.33, 10.74] were more likely to develop stunting than those living in households with one under-five child. Children whose mothers worked as merchants $[\mathrm{AOR}=4.03,95 \%$ CI: $1.60,10.17]$ and farmers [AOR $=3.92,95 \% \mathrm{CI}: 1.89$, 8.16] were more likely to be stunted than children whose mothers worked as house wives. Children who breast fed for less than two years $[\mathrm{AOR}=5.61,95 \% \mathrm{CI}$ : 1.49 , 11.08] were more likely to be stunted than those who breast fed for two or more years. Children who were exclusively breast fed for less than six months [AOR = 3.27, 95\% CI: 1.21, 8.82] and greater than six months $[\mathrm{AOR}=7.62,95 \% \mathrm{CI}: 1.80,12.23]$ were more likely to develop stunting than children who were exclusively breast fed for the first 6 months. Children who bottle fed $[\mathrm{AOR}=3.30,95 \% \mathrm{CI}: 1.33,8.17)]$ and fed by hand [AOR $=3.04,95 \% \mathrm{CI}: 1.46,6.32]$ were more likely to be stunted than children who fed their complementary food using spoon/cup (Table 2).

\section{Discussion}

This study intended to identify the factors associated to stunting among children age of 24 to 59 months using analytic study design. However, certain limitations may arise in the study such as recall bias and absence of data on: maternal nutrition, heights of the mothers, household food security and parasitic infections. There may be also misclassification of case and control, because of it is very difficult to get accurate age in country like Ethiopia. Efforts were made to get accurate age by asking for immunization card of the participants during the census. Lastly, since case-control study design was employed, it

In this study participants living in households with high number of under-five children were about 4 times more likely to develop stunting than those living in households with least number of under-five children. does not enable to establish temporality. 
Table 2 Factors independently associated with stunting among children of age 24 to 59 months in Meskan district, Gurage Zone, South Ethiopia, March 2013

\begin{tabular}{|c|c|c|c|c|}
\hline Variable & $\begin{array}{c}\text { Case } \\
\text { № (\%) }\end{array}$ & $\begin{array}{l}\text { Control } \\
\text { № (\%) }\end{array}$ & $\begin{array}{l}\text { Crude OR } \\
(95 \% \mathrm{Cl})\end{array}$ & $\begin{array}{c}\text { Adjusted OR } \\
(95 \% \mathrm{Cl})\end{array}$ \\
\hline \multicolumn{5}{|l|}{ Family size } \\
\hline 2-4 (ref.) & 24(19.8) & $44(36.4)$ & - & - \\
\hline $5-7$ & $73(60.3)$ & $60(49.6)$ & $2.231(1.22,4.08)^{* *}$ & $2.97(1.41,6.29)^{* *}$ \\
\hline $8-10$ & 24(19.8) & $17(14)$ & $2.59(1.17,5.74)^{*}$ & $4.44(1.65,11.95)^{* *}$ \\
\hline \multicolumn{5}{|c|}{ Number of under 5 children } \\
\hline 1 (ref.) & $41(33.9)$ & $66(54.5)$ & - & - \\
\hline 2 & $60(49.6)$ & 48(39.7) & $2.01(1.17,3.47)^{*}$ & $1.88(0.97,3.61)$ \\
\hline 3 & $20(16.5)$ & $7(5.8)$ & $4.60(1.79,11.83)^{* *}$ & $3.77(1.33,10.74)^{*}$ \\
\hline \multicolumn{5}{|l|}{ Maternal Occupation } \\
\hline Farmer & $50(41.3)$ & $38(31.4)$ & $2.018(1.15,3.55)^{* *}$ & $3.92(1.89,8.16)^{* *}$ \\
\hline Merchant & $26(21.5)$ & 14(11.6) & $2.85(1.35,6.03)^{*}$ & $4.03(1.60,10.17)^{* *}$ \\
\hline House wife (ref.) & $45(37.2)$ & $69(57.0)$ & - & - \\
\hline \multicolumn{5}{|c|}{ Duration of breast feeding } \\
\hline$<24$ months & 16(13.2) & $4(3.3)$ & $4.46(1.44,10.8)^{* *}$ & $5.61(1.49,11.08)^{*}$ \\
\hline$\geq 24$ months(ref.) & 105(86.8) & 117(96.7) & - & - \\
\hline \multicolumn{5}{|l|}{ Duration of EBF } \\
\hline For 6 months (ref.) & $86(71.1)$ & 105(86.8) & - & - \\
\hline Below 6 months & $21(17.4)$ & 13(10.7) & $1.972(0.93,4.17)$ & $3.27(1.21,8.82)^{*}$ \\
\hline Above 6 months & 14(11.6) & $3(2.5)$ & $5.69(1.58,10.5)^{* *}$ & $7.62(1.80,12.23)^{* *}$ \\
\hline \multicolumn{5}{|l|}{ Method of feeding } \\
\hline Spoon \& Cup (ref.) & $50(41.3)$ & $77(63.6)$ & - & - \\
\hline Bottle & $29(24.0)$ & 14(11.6) & $3.190(1.54,6.62)^{* *}$ & $3.30(1.33,8.17)^{* *}$ \\
\hline Hand & $42(34.7)$ & $30(24.8)$ & $2.16(1.19,3.88)^{* *}$ & $3.04(1.46,6.32)^{* *}$ \\
\hline
\end{tabular}

Variables included in the adjusted model are wealth index, child age, diarrhea, ARI, type of complementary food, number of food group, delivery attendance, mother hand washing practice, source of drinking water and maternal knowledge.

${ }^{*} p<0.05,{ }^{* *} p<0.01$, (ref.) - reference category.

This is consistent with community based studies conducted in southern Brazil and South Africa [12,17]. Similarly children living in households with eight to ten family members were 4.44 and living in household with five to seven family members were 2.97 times more likely to develop stunting compared with those living in household with two to four family members. This might be due to resource depletion which exposed to poverty and decrement in food availability and also suggesting that there is more competition for available food when the household is large. This is in line with studies conducted in Northeastern Brazil, South Africa and Ethiopia $[13,17,18]$. But which is inconsistent with study conducted in Uganda [30].

Children whose mothers worked as merchant and farmer were more likely to develop stunting than children whose mothers worked as house wives. This might be due to decreased contact time to the child that brings short period of exclusive breast feeding, early cessation of breast feeding, increase exposure to bottle feeding and improper complementary food, which may have a large negative effect on the growth children. Our results are not consistent with studies that had shown a protective effect of maternal employment by increasing income and female autonomy. Employment may also positively influence food security, quality of diet and use of health services [21]. The difference is probably due to the fact that factors like child caring practice were overlooked in the previous study.

The likelihood of stunting was` higher among children who exclusively breast fed below or above the age of six months compared with who exclusively breast fed for six months. This finding was in line with study conducted different areas $[17,20,23]$. Inappropriate timing for introducing some kinds of complementary food to a child may affect his/her nutritional status because his/her digestive and immune systems are not yet mature. Introducing supplements before earlier, especially under unhygienic conditions, could be an important cause of malnutrition. On the other hand some studies demonstrated 
that association was not observed [22,30]. The difference is probably due to difference in study design as well as geographical difference.

Our study showed that feeding complementary food using bottle and by hand increases the risk of stunting among children. This finding is consistent with other studies conducted in our country [23] in which feeding using bottle and hand were associated with increase the odds stunting.

\section{Conclusion}

This study showed number of under-five children, family members, maternal occupation, duration of breast feeding, duration of exclusive breast feeding \& method of feeding complementary food were independently associated with stunting. Thus, national public health intervention programmer and stakeholder working on improving child nutrition should focus on these determinants to reduce stunting. Health extension workers shall educate mothers/caretakers on the importance of exclusive breast feeding, methods of complementary feeding and adequate spacing between children. Program planner and policy makers should consider \& strengthen collaboration and coordination of nutritional program that aimed to alleviate nutritional deficiencies and family health program.

\section{Competing interests}

The authors declare that they have no competing interests.

\section{Authors' contributions}

FT involved from the inception to design, acquisition of data, analysis and interpretation, drafting the manuscript, SA involved in the inception to design, analysis and interpretation and revise the manuscript. LD involved in the inception to design, analysis and interpretation and revises and edits the manuscript for the final submission. All authors read and approved the final manuscript.

\section{Acknowledgements}

We would like to extend our deepest gratitude to the Jimma University for financing this study. Our appreciation goes to the data collectors and supervisors. Lastly, our special thanks also go to mothers who participated in the study.

\section{Author details}

${ }^{1}$ Arba Minch Health Science College, Arba Minch, Ethiopia. ${ }^{2}$ College of Public Health and Medical Sciences, Department of Epidemiology, Jimma University, Jimma 378, Ethiopia.

Received: 26 November 2013 Accepted: 29 July 2014

Published: 7 August 2014

\section{References}

1. World Health Organization: Maternal, Infant and Young Child Nutrition. Geneva: 2011.

2. Black RE, Allen LH, Bhutta ZA, Caulfield LE, Onis M, Ezzati M, Mathers C, Rivera J: Maternal and child under nutrition: global and regional exposures and health consequences. Lancet 2008 371(9608):243-260.

3. UNDP: Children Malnutrition and Horizontal Inequalities in Sub-Saharan Africa. 2012.

4. World Health Organization: Nutrition for Health and Development: A Global Agenda for Combating Malnutrition. Geneva: 2000.
5. Underwood BA: Health and Nutrition in Women, Infants, and Children: Overview of the Global Situation and the Asian Enigma. Nutr Rev 2002, 60:5.

6. Onis MO, Blossner M, Borghi E: Prevalence and trends of stunting among pre-school children, 1990-2020. NS Public Health Nutrition 2011, 15(1):142-148

7. Central Statistical Agency [Ethiopia] and ICF International: Ethiopia Demographic and Health Survey 2011. Addis Ababa, Ethiopia and Calverton, Maryland, USA: Central Statistical Agency and ICF International; 2012.

8. Jesmin A, Yamamoto SS, Malik AA, Haque A: Prevalence and Determinants of Chronic Malnutrition among Preschool Children. J Health Popul Nutr 2011, 29(5):494-499.

9. Dewey KG, Begum KB: Long-term consequences of stunting in early life. Mat Child Nutri 2011, 7(3):5-18.

10. Kar BR, Rao SL, Chandramouli BA: Cognitive development in children with chronic protein energy malnutrition. BMC Behavioral and Brain Functions 2008, 4:31

11. Morris SS, Cogill B, Uauy R: Effective international action against under nutrition: why has it proven so difficult and what can be done to accelerate progress. Lancet 2008, 371:608-621.

12. Vitolo MR, Gama CM, Bortolini GA, Campagnolo PD, Dranchler ML: Some risk factors associated with overweight, stunting and wasting among children under 5 years old. J Pediatr 2008, 84(3):251-257.

13. Cristina R, Israel $P$, Sa Leal V, Oliveira JS, Cristina S, Augusta LA, Rissin A, Filho $\mathrm{MB}$ : Determinants of stunting in children under five in Pernambuco, Northeastern Brazil. Rev Saude Publica 2011, 45(6):1079-1087.

14. Zottarelli LK, Sunil TS, Rajaram S: Influence of parental and socioeconomic factors on stunting in children under 5 years in Egypt. Eastern Mediterranean 2007, 13(6):1330-1342.

15. Reyes H, Perez-Cuevas R, Sandoval A, Castillo R, Santos JI, Doubova SV, Gonzalo G: The family as a determinant of stunting in children living in conditions of extreme poverty: a case- control study. BMC Public Health 2004, 4(57). doi:10.1186/1471-2458-4-57.

16. Das S, Sahoo H: An Investigation into Factors Affecting Child Under nutrition in Madhya Pradesh. Anthropologist 2011, 13(3):227-233.

17. Mamabolo RL, Alberts M, Steyn NP, Waal HA, Levitt NS: Prevalence and determinants of stunting and overweight in 3-year-old black South African children residing in the Central Region of Limpopo Province, South Africa. Public Health Nutr 2005, 8(5):501-508.

18. Umeta M, Clive EW, Hans V, Haidar J, Joseph H: Factors Associated with Stunting in Infants Aged 5-11 Months in the Dodota-Sire District, Rural Ethiopia. J Nutri 2002, 133:1064-1069.

19. Ergin F, Okyay P, Atasoylu G, Beser E: Nutritional status and risk factors of chronic malnutrition in children under five years of age in Aydin. Turkish J Pediatr 2007, 49:283-289.

20. Kamal M: Socio-economic Determinants of Severe and Moderate Stunting among Under-Five Children of Rural Bangladesh. Mal J Nutr 2011, 17(1):105-118.

21. Willey AB, Cameron N, Norris AS, Pettifor JM, Griffiths PL: Socioeconomic predictors of stunting in preschool children: a populationbased study from Johannesburg and Soweto. S Afr Med J 2009, 99:450-456.

22. Farid-ul-Hasnain S, Sophie R: Prevalence and risk factors for Stunting among children under 5 years: a community based study from Jhangara town, Dadu Sindh. JPMA 2010, 60(1):41-44.

23. Teshome B, Kogi-Makau W, Getahun Z, Taye G: Magnitude and determinants of stunting in children under-five years of age in food surplus region of Ethiopia: The case of West Gojam Zone. Ethiop J Health Dev 2009, 23(2):98-106.

24. Abuya BA, Ciera J, Kimani-Murage E: Effect of mother's education on child's nutritional status in the slums of Nairobi. BMC Pediatr 2012, 12:80.

25. Taguri A, Betilmal I, Mahmud SM, Ahmed AM, Goulet O, Galan P, Hercberg S: Risk factors for stunting among under-fives in Libya. Public Health Nutr 2009, 12(8):1141-1149.

26. Muchina EN, Waithaka PM: Relationship between breastfeeding practices and nutritional status of children aged 0-24 months in Nairobi, Kenya. AJFAND 2011, 10(4):2358-2378.

27. Awogbenja MD, Ugwuona FU: Feeding Practices and Nutritional Status of Under- Five Children in Nasarawa State, Nigeria. PAT 2010, 6(1):23-35. 
28. Ramli, Agho KE, Inder KJ, Bowe SJ, Jacobs J, Dibley MJ: Prevalence and risk factors for stunting and severe stunting among under-fives in North Maluku province of Indonesia. BMC Pediatr 2009, 9:64.

29. Prema R, Hema SG: Under nutrition \& risk of infections in preschool children. Indian J Med Res 2009, 130:579-583.

30. Turyashemererwa FM, Kikafunda JK, Agaba E: Prevalence of Early Childhood Malnutrition and Influencing Factors in Peri-Urban Areas of Kabarole District, Western Uganda. AJFAND 2009, 9:4.

doi:10.1186/1471-2458-14-800

Cite this article as: Fikadu et al:: Factors associated with stunting among children of age 24 to 59 months in Meskan district, Gurage Zone, South Ethiopia: a case-control study. BMC Public Health 2014 14:800.

\section{Submit your next manuscript to BioMed Central and take full advantage of:}

- Convenient online submission

- Thorough peer review

- No space constraints or color figure charges

- Immediate publication on acceptance

- Inclusion in PubMed, CAS, Scopus and Google Scholar

- Research which is freely available for redistribution 